\title{
Stereotip Tenaga Kerja Indonesia dalam Iklan RoboVac
}

\author{
Muhammad Masyaril Hraoom \\ Program Studi Ilmu Komunikasi, Universitas Muhammadiyah Yogyakarta \\ masyarilu@gmail.com \\ Azhar Rizky Bumi \\ Program Studi Ilmu Komunikasi, Universitas Muhammadiyah Yogyakarta \\ azharrizky58@gmail.com \\ Pradipta Ade Arkan \\ Program Studi Ilmu Komunikasi, Universitas Muhammadiyah Yogyakarta \\ ade.arkan70@gmail.com \\ Diserahkan: 6 Februari 2020; Direvisi: 26 Maret 202 1; Diterima: 26 Maret 2021
}

\begin{abstract}
Becoming a TKI is one of the paths that many Indonesians choose and is also one of the government's programs to reduce unemployment in Indonesia. A RoboVac advertisement from Malaysia in the form of a robot vacuum cleaner was deemed offensive and created a bad stereotip against migrant workers. This research looks at the stereotips of Indonesian workers in RoboVac advertisements that use the word "fire your Indonesian maid now (fire your Indonesian maid now)." This study was analyzed using Roland Barthes' semiotics method. As for the words that appear, they are cornering the migrant workers because at such a low price employers can employ migrant workers, and there is a compulsion to immediately fire migrant workers who are already working and replace them with robots.
\end{abstract}

Keywords: RoboVac Ads, Demeaning, Stereotip, Semiotic.

\begin{abstract}
Abstrak
Menjadi seorang TKI merupakan salah satu jalan yang banyak dipilih oleh warga Indonesia dan juga salah satu program pemerintah untuk mengurangi pengangguran di Indonesia. Sebuah iklan RoboVac asal Malaysia berupa robot penyedot debu ternyata dianggap diangap menyinggung dan menimbulkan stereotip yang buruk terhadap TKI. Penelitian ini melihat stereotip tenaga kerja Indonesia dalam iklan RoboVac yang menggunakan kata "fire your Indonesian maid now (pecat pembantu Indonesia mu sekarang)." Penelitian ini dianalisis menggunakan metode semiotika Roland Barthes. Adapun kata-kata yang muncul merupakan kata-kata yang menyudutkan para TKI karena dengan harga yang murah dengan itu majikan bisa mempekerjakan TKI, dan terdapat pemaksaan untuk secepatnya memecat TKI yang sudah bekerja dan menggantikannya dengan robot.

Kata Kunci: Iklan RoboVac, Merendahkan, Stereotip, Semiotik.
\end{abstract}




\section{PENDAHULUAN}

Iklan adalah berita atau pesan untuk membujuk orang agar tertarik pada barang atau jasa yang ditawarkan, iklan biasanya dipromosikan melalui media periklanan seperti, televisi, radio, koran, majalah dan internet. Iklan mengandung pemberitahuan kepada masyarakat dan bersifat mengajak pembaca agar melakukan apa yang diinginkan Iklan tidak terbatas pada produk, melainkan juga pada informasi, ajakan untuk melakukan suatu hal. Banyaknya pengusaha yang menjual produk yang sama, menuntut pengusaha untuk terus melakukan inovasi agar dapat bertahan dalam persaingan. Demi memenangkan persaingan, pengusaha melakukan berbagai strategi untuk mengenalkan produknya serta meningkatkan penjualannya. Salah satu strategi perusahaan yaitu melalui promosi melalui iklan.

Tujuan mengiklankan sebuah produk adalah untuk memengaruhi sikap khalayak, dalam hal ini tentunya sikap dari konsumen (Jefkins, 1996). Secara garis besar tujuan dari iklan adalah untuk membujuk atau mendorong orang lain agar menjadi tertarik untuk menggunakan suatu produk/jasa. Tidak heran di era saat ini perusahaan tidak hanya berlomba-lomba dalam membuat produk terbaik, namun juga berlomba-lomba membuat iklan produk yang menarik untuk manarik minat konsumen agar membeli produknya.

Salah satu iklan yang menyinggung pihak tertentu adalah iklan RoboVac. RoboVac adalah perusahaan robot penyedot debu asal Malaysia. Perusahaan asal Malaysia tersebut dinilai cenderung merendahkan WNI asal Indonesia melalui sebuah iklan yang mereka produksi. Pesan dalam produk itu mengajak konsumen memecat Pembantu Rumah Tangga (PRT) asal Indonesia dan menggantikannya dengan robot. Seharusnya iklan harus bersifat positif dan tidak bersifat diskrimitatif.

Iklan dibuat bukan hanya untuk menjual suatu produk tetapi juga membentuk citra, nilai, dan konsep suatu produk (Winarni, 2010). Iklan merupakan sebuah titik persinggungan antara kepentingan komersil si pembuat produk dengan khalayak sebagai konsumen barang dan jasa (Wahyuni, 2010). Baik produsen produk maupun pembuat iklan akan menciptakan konsep yang menarik dengan tujuan mampu menarik perhatian khalayak. Pengiklan berusaha berkomunikasi dengan target audiens dengan keyakinan yang ada (Kim dan Lowry, 2005). Periklanan kini cenderung menjadi sarana legimitasi hegemoni ideologi maupun pelestari dominasi ideolog patriarkis (Astuti, 2016). Pengiklan percaya bahwa penggunaan stereotip membuat lebih mudah untuk berkomunikasi dengan target audiens dan menjual produk mereka daripada penggunaan beberapa nilai dan keyakinan yang realistis (Kim dan Lowry, 2005).

Stereotip adalah konsepsi yang secara tetap (fixed) melekat pada kelompok tertentu. Ketika melakukan stereotip pada seseorang maka, hal pertama yang kita kerjakan adalah mengidentifikasi orang tersebut sebagai anggota bagian dari kelompok tertentu, kemudian memberikan penilaian atas dasar individu yang bersangkutan. Jadi ketika berinteraksi dengan orang lain, presepsi pertama yang muncul adalah memandang latarbelakang orang tersebut baru kemudian berpresepsi atas kemampuan individu. Konsepsi yang melekat pada orang lain ini dapat bersifat positif maupun negatif (Sukmono dan Junaedi, 2014).

Iklan RoboVac tersebut jelas menyinggung bangsa Indonesia. Dapat diartikan dalam kata - kata tersebut bahwa produk RoboVac bisa bekerja lebih baik dari PRT asal Indonesia. Penelitian ini berangkat dari iklan dan TKI menemukan bahwa citra Indonesia yang tergambarkan dalam dua iklan tentang TKI Malaysia adalah rendah (karena tenaga kerja disamakan dengan barang) dan tidak lebih baik dari fungsi robot pembersih rumah tangga (Pratiwi, 2015). Dalam iklan yang beredar di media cetak Malaysia pada tahun 2012, kata-kata yang muncul merupakan kata-kata yang menyudutkan para TKI karena dengan harga yang murah dengan itu majikan bisa mempekerjakan TKI. Sementara dalam iklan yang muncul di tahun 2015 terjadi justifikasi yang dilakukan melalui dua komposisi yaitu: komposisi gambar dan tulisan. Terdapat pemaksaan untuk secepatnya memecat TKI yang sudah bekerja dan menggantikannya dengan robot. Dengan demikian, penelitian ini melihat stereotip tenaga kerja Indonesia dalam iklan RoboVac. 


\section{METODE PENELITIAN}

Dalam penelian ini penulis menggunakan jenis penelitian deskriptif kualitatif dengan paradigma kritis. Jika secara lebih operasional, untuk membedah obyek penelitian ini, kami menggunakan metode semiotika. Obyek penelitian dalam penelitian ini adalah iklan RoboVac tahun 2015. Obyek penelitian ini dibedah dengan memakai cara analisis semiotika Roland Barthes yang mengembangkan pemikiran dari Ferdinand De Saussure.

Semiotika atau dalam Bahasa Inggris disebut semiotic, berasal dari Bahasa Yunani, semieon yang artinya tanda. Semiotika diperkenalkan oleh Ferdinand De Saussure (1857-1913). Pertama, tanda (sign $)$ terdiri dari dua aspek, yaitu penanda (signifiant), dan petanda (signified). Penanda dapat diartikan sebagai bentuk/wujud fisik. Penanda dapat berupa bunyi, gambar, huruf, visual dan sejenisnya. Petanda adalah konsep arti dari apa yang ditandai. Relasinya antara kedua hal tersebut bersifat "diadaadakan" (arbitrary), yang artinya tidak ada relasi yang bersifat alamiah diantara penanda dan petanda. Tetapi, relasi yang bersifat "diada-adakan" terikat oleh konvensi atau struktur. Secara etimologis, Saussure menuturkan bahwa semiotika sebagai ilmu yang mengkaji tentang tanda menjadi bagian dari kehidupan sosial (Piliang, 2003). Semiotika dielaborasi menjadi hubungan tripartit yaitu tanda (sign) yang merupakan gabungan dari penanda (signifier) dan petanda (signified) (Fiske dan Hartley, 1996).

Kedua adalah langue dan parole. Langue adalah abstaksi dan artikulasi bahasa pada tingkat sosial budaya, berbeda dengan langue, parole adalah ekspresi bahasa pada tingkat individu. Langue jugs bisa kita sebut dengan sistem bahasa yang berlaku, sedangkan parole adalah bagaimana individu berbahasa dalam sistem tersebut.

Setelah pemikiran Saussure, Rolan Barthes melanjutkan pemikiran tersebut dengan memberi telaah kepada interaksi diantara teks dengan pengalaman personal dan kultural si pengguna. Interaksi atau hubungan antara konvensi dalam teks dengan tatanan penandaan (order of signification), yang meliputi primary signification atau denotasi (makna sebenarnya sesuai kamus) dan secondary signification atau konotasi (makna ganda yang lahir dari pengalaman kultural dan personal). Arti konotasi inilah yang kemudian menjadi berkembang sehingga menjadi mitos. Pada penelitian ini, penulis berusaha melakukan analisis semiotika, mulai dari primary signification hingga secondary signification pada iklan RoboVac.

\begin{tabular}{l|l}
$\begin{array}{l}\text { 1. Signifier } \\
\text { (Penanda) }\end{array}$ & $\begin{array}{c}\text { 2. Signified } \\
\text { (Petanda) }\end{array}$ \\
\cline { 1 - 1 } Denotatif Sign (Tanda Denotatif) & \\
\hline $\begin{array}{l}\text { 4. CONNOTATIF SIGNIFIER } \\
\text { (PENANDA KONOTATIF) }\end{array}$ & $\begin{array}{c}\text { 5. CONNOTATIF SIGNIFIED } \\
\text { (PETANDA KONOTATIF) }\end{array}$ \\
\hline
\end{tabular}

6. CONNOTATIF SIGN (TANDA KONOTATIF)

Gambar 1. Pemaknaan Tanda dalam Semiotika Roland Barthes

\section{HASIL DAN PEMBAHASAN}

Pertama, iklan ini muncul pada tahun 2015 lalu dalam bentuk spanduk. Jika dilihat sekilas tidak ada yang aneh dalam iklan ini. Namun, bila dicermati ada kata - kata yang menyinggung pihak lain yaitu Indonesia. Kata - kata tersebut yaitu "Fire Tour Indonesian Maid Now" yang artinya pecat pembantu Indonesia. 


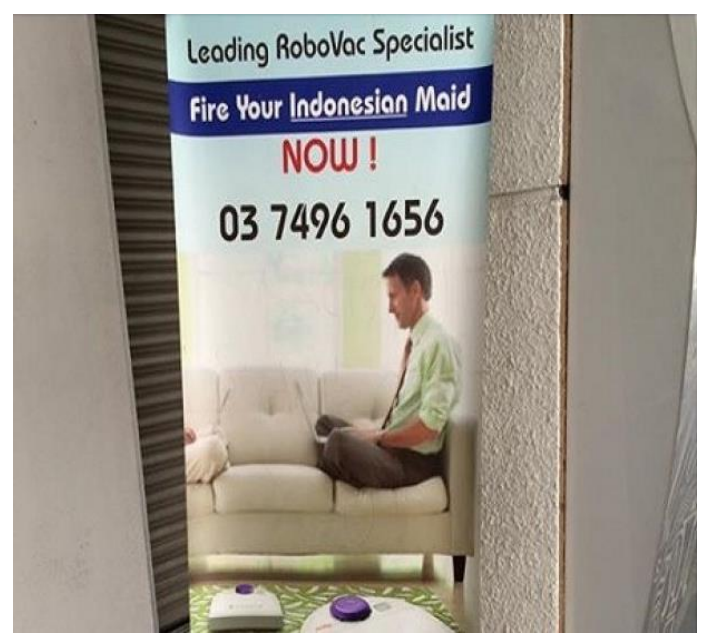

Gambar 2. Iklan Leadinh RoboVac Specialist

Pencitraan merupakan gambaran yang mewakili suatu negara dalam bentuk visualisasi, termasuk iklan. Pada iklan tersebut membuktikan bahwa stereotip mayoritas masyarakat Malaysia terhadap TKI sangat direndahkan. Walaupun dalam Pasal 3 Undang-Undang Nomor 39 Tahun 2004 dinyatakan bahwa tujuan penempatan dan perlindungan calon buruh migran adalah:

a. memberdayakan dan mendayagunakan tenaga kerja secara optimal dan manusiawi;

b. menjamin dan melindungi calon buruh migran sejak di dalam negeri, di negara tujuan, sampai kembali ke tempat asal di Indonesia;

c. meningkatkan kesejahteraan buruh migran dan keluarganya.

Hal ini juga menimbulkan pertanyaan tentang kesejahteraan dan perlindungan TKI. Penempatan TKI di luar negeri itu rentan dengan perlakuan tidak manusiawi atau perlakuan eksploitatif lainnya di negara penerima. Oleh karna itu, pemerintah dinilai belum bisa dalam menjamin kesejahteraan TKI di luar negeri (Adharinal, 2012).

Tulisan terdiri dari Leading RoboVac Specialist, Fire Your Indonesian Maid NOW! Dalam tulisan Fire Your Indonesian Maid jika dibandingkan dengan tulisan di atasnya yakni Leading RoboVac Specialist terdapat perbedaan bahwa tulisan Fire Your Indonesian Maid ditonjolkan dengan ribbon banner warna biru tua. Warna yang dipilih jauh lebih gelap dibandingkan warna latar dari standing banner yakni biru muda yang juga menjadi latar belakang tulisan Leading RoboVac Specialist. Warna yang digunakan. Pada tulisan Leading RoboVac Specialist adalah warna hitam. Warna hitam pada teks dapat bermakna kekuasaan, kemewahan, kuat, seksi, ajaib, jahat dan mahal. Jika dikaitkan dengan makna teks yang berusaha menggambarkan pengiklan sebagai pemimpin dalam spesialisasi RoboVac, maka warna hitam berusaha menguatkan kekuasaan dan kekuatan RoboVac Malaysia.

Melalui analisis semiotika Roland Barthes, penulis menemukan kalimat yang deskrimitatif yang bertuliskan "Fire Your Indonesian Maid Now" yang artinya pecat pembantu Indonesia. Pengiklan percaya bahwa penggunaan stereotip membuat lebih mudah untuk berkomunikasi dengan target audiens dan menjual produk mereka daripada penggunaan beberapa nilai dan keyakinan yang realistis (Kim dan Lowry, 2005).

Secara denotasi iklan ini menggambarkan pria yang sedang duduk di bangku yang sedang bersantai sambil menunggu robot miliknya bekerja membersihkan lantai. Secara konotasi iklan RoboVac menjelaskan kepada khalayak bahwa robotnya lebih baik dibandingkan para pekerja TKI. Stereotip terjadi karena manusia cenderung melakukan konstruksi kategoris, dimana dengan ini pikiran manusia memproses informasi lebih efisien sekali dibentuk, kategori itu akan menjadi dasar dari penilai awal, seperti, stereotip. Dengan kategori yang terbentuk, stereotip akan dilakukan pada anggota kelompok yang mendapat atribusi sebagaimana anggota kelompok lain dalam kelompok yang sama. Atribusi ini, sebagai mana telah disampaikan sebelumnya, bisa bernilai evaluasi positif maupun negatif 
atas anggota kelompok tersebut. Stereotip bertujuan pada keanggotaan dalam kategori tertentu, seperti etnis, ras, seks, dan pekerjaan (Neulip dalam Junaedi, 2014).

Mitos yang dite

mukan dalam penelitian ini adalah robot diyakini lebih baik dibandingkan para pekerja rumah tangga khususnya asal Indonesia (TKI), karena sepintar apapun robot tidak akan bisa mengalahkan kecerdasan yang dimiliki manusia. Hal ini bahkan dapat mengarah kepada perbudakan modern dan berlawanan dengan penegakan hak asasi manusia.

Secara kodrati, manusia memiliki daya tarik lebih baik dibandingkan sebuah robot, disadari atau tidak, TKI menjadi obyek yang menarik, iklan RoboVac dengan model pria yang sedang duduk santai dengan robotnya tidak bisa menggambarkan bahwa robot bisa bekerja lebih baik dari pada manusia. ketika kita melakukan stereotip pada seseorang maka, hal pertama yang kita kerjakan adalah mengidentifikasi orang tersebut sebagai anggota bagian dari kelompok tertentu, sehabis itu memberi penilaian atas dasar individu yang bersangkutan. Jadi ketika berinteraksi dengan orang lain, presepsi pertama yang muncul adalah memandang latar belakang orang tersebut baru kemudia berpresepsi atas kemampuan individu. Konsepsi yang melekat pada orang lain ini dapat bersifat positif maupun negatif (Sukmono dan Junaedi, 2014).

Dalam penelitian ini menemukan bahwa perusahaan asal Malaysia tersebut menilai tenaga kerja Indonesia (TKI) hanya berdasarkan persepsi mereka dan hanya memandang sebelah mata saja tanpa mereka sadari bahwasannya kata-kata yang mereka tuliskan bisa saja merusak atau memicu kesalah pahaman antar Negara. Selain itu, iklan RoboVac tersebut dapat menimbulkan persepsi bahwa Indonesia $=$ Bangsa Pembantu dan Pembantu $=$ Indonesia kepada khalayak.

\section{KESIMPULAN}

Berdasarkan uraian analisa data pada bab sebelumnya, maka peneliti dapat menarik beberapa kesimpulan makna pesan yang terkandung adalah citra Indonesia yang tergambarkan dalam iklan Robovac tentang TKI adalah rendah (karena tenaga kerja disamakan dengan barang) dan tidak lebih baik dari fungsi robot pembersih rumah tangga, dalam iklan robovac yang tertulis di banner, katakata yang muncul merupakan kata-kata yang menyudutkan para TKI karena dengan harga yang murah dengan itu majikan bisa mempekerjakan TKI, dan terdapat pemaksaan untuk secepatnya memecat TKI yang sudah bekerja dan menggantikannya dengan robot.

\section{REFERENSI}

Hidayat, H. (2017). Perlindungan Hak Tenaga Kerja Indonesia di Taiwan dan Malaysia dalam Perspektif Hak Asasi Manusia. Jurnal HAM, 8(2), 105-115. doi:http://dx.doi.org/10.30641/ham.2017.8.105-115

Pratiwi, M., \& Yusriana, A. (2018). REFLEKSI CITRA INDONESIA SEBAGAI DAMPAK POLITIK MIGRASI TKI KE MALAYSIA. Jurnal Ilmiah Komunikasi Makna, 6(1), 46-59. doi:http://dx.doi.org/10.30659/jikm.6.1.46-59

Astuti, Y. D. (2016). MEDIA DAN GENDER (Studi Deskriptif Representasi Stereotipe Perempuan dalam Iklan di Televisi Swasta). Profetik: Jurnal Komunikasi, 9(2).

Jefkins, F. (1996). Periklanan. Edisi Ketiga. Jakarta: Elangga.

Adharinal. (2012). PERLINDUNGAN TERHADAP TENAGA KERJA INDONESIA IRREGULAR DI LUAR NEGERI. Jurnal Rechts Vinding (Media Pembinaan Hukum Nasional). 158.

Khusnaeni, N. L., Yulianto, E., \& Sunarti. (2017). Pengaruh Iklan Terhadap Sikap Konsumen Serta Dampaknya Pada Keputusan Pembelian. Jurnal Administrasi Bisnis, 50.

Sukmono, F. G., \& Junaedi, F. (2014). Komunikasi Multikultur. Yogyakarta: Buku Litera Yogyakarta.

Virtazia, D dan Hariyanti,P. (2019). Komunikasi dalam Media Digital. Yogyakarta, Buku Litera Yogyakarta. 